УДК 547.913

\title{
ПОЛУЧЕНИЕ БИОКОМПОЗИТНЫХ ФОСФОР-КАЛИЙНЫХ УДОБРЕНИЙ ПРОЛОНГИРОВАННОГО ДЕЙСТВИЯ НА ОСНОВЕ КОРЫ ЛИСТВЕННИЦЫ
}

\author{
(C) Е.В. Веприкова ${ }^{1 *}$, Б.Н. Кузнецов ${ }^{1,2}$, Н.В. Чесноков ${ }^{1,2}$ \\ ${ }^{1}$ Институт химии и химической технологии СО РАН, Федеральный \\ исследовательский центр «Красноярский научный центр СО РАН», \\ Академгородок, 50-24, Красноярск, 660036 (Россия), e-mail: veprikova2@mail.ru \\ ${ }^{2}$ Сибирский фредеральный университет, пр. Свободный, 79, Красноярск, \\ 660041 (Россия)
}

Показана возможность получения биокомпозитных удобрений пролонгированного действия пропиткой пористой подложки из коры лиственницы водным раствором $\mathrm{K}_{2} \mathrm{HPO}_{4}$. Определены условия щелочной обработки коры лиственницы, позволяющие получать пористые подложки с низким содержанием водорастворимых веществ, токсичных для растений. В вегетационных тестах выявлено ростостимулирующее действие пористых подложек из коры лиственницы в зависимости от содержания в них водорастворимых веществ. Изучено влияние природы соли, температуры сушки пропитанной подложки и условий ее кислотной обработки на вымывание водой фосфатов и калия из биокомпозитных удобрений. Осуществлен подбор условий получения, обеспечивающих наибольшую устойчивость фосфоркалийного удобрения к вымыванию водой активных компонентов. Установлено, что удобрение на основе коры лиственницы способно к медленному выделению активных компонентов в течение длительного времени. Экспериментально установлено, что из удобрения, полученного в оптимальных условиях, в течение 10 сут. вымывается водой 43,6\% фосфатов и 53,3\% калия, что обеспечивает эффект его пролонгированного действия. Показано, что разработанное биокомпозитное фосфор-калийное удобрение по устойчивости к вымыванию фосфатов и калия превосходит промышленное гранулированное удобрение.

Ключевые слова: биокомпозитное удобрение, кора лиственницы, пористая подложка, пропитка, калий, фосфаты, пролонгированное действие.

Исследования выполнены при финансовой поддержке РФФИ и Правительства Красноярского края в рамках научного проекта № 16-43-242083.

В работе использованы приборы центра коллективного пользования Федерального исследовательского иентра «Красноярский научный центр СО РАН»

\section{Введение}

Лиственница относится к основным лесообразующим породам на территории России и используется в различных лесоперерабатывающих отраслях. Отличительная особенность лиственницы - наличие толстой коры, на долю которой, в зависимости от возраста деревьев, приходится от 16 до $31 \%$ общего объема

Веприкова Евгения Владимировна - старший научный сотрудник, кандидат технических наук, e-mail: veprikova2@mail.ru

Чесноков Николай Васильевич - директор, доктор химических наук, тел. (391) 205-19-50, e-mail: cnv@icct.ru Кузнецов Борис Николаевич - заведующий лабораторией, доктор химических наук, профессор, Институт химии и химической технологии СО РАН, заведующий кафедрой, Сибирский федеральный университет,

тел. (391) 249-48-94, e-mail: bnk@icct.ru ствола. Многотоннажные отходы коры, образующиеся при получении древесины, в соответствии с требованиями рационального природопользования должны перерабатываться в востребованные продукты различного назначения. Так, из коры лиственницы можно получать прессованные материалы, сорбенты [1, 2]. Важным направлением утилизации коры лиственницы является ее хими-

\footnotetext{
* Автор, с которым следует вести переписку.
} 
ческая переработка, позволяющая получать дубильные вещества, красители, пектин, уникальные биоактивные вещества и др. [3-5]. В литературе показана возможность применения пектина из коры лиственницы для создания наноструктурированных композитов [6]. Биоконверсия остатка экстракции коры в присутствии грибов Trichoderma дает возможность получать препараты защиты и стимуляции роста растений [7].

Традиционным направлением утилизации отходов коры лиственницы является получение компостов с разнообразными минеральными добавками $[8,9]$. Также в качестве удобрений и мульчирующей добавки целесообразно применять остатки экстрагирования коры [10]. Древесная кора является перспективным сырьем для получения пористых подложек, на которые можно наносить разнообразные вещества. Заполнение пор подложек микро- и макроэлементами, необходимыми для питания растений, позволяет получать органоминеральные удобрения. Медленное выделение таких активных компонентов из пор подложки в почвенный раствор уменьшает риск их передозировки в почве и обусловливает эффект длительного действия удобрений. Так, в литературе показана возможность получения биокомпозитных удобрений пролонгированного действия на основе пористых подложек из коры березы и ее луба [11-13]. Физико-химические свойства и строение подложек способствуют закреплению активных компонентов (азота, калия, фосфора) на их поверхности в процессе пропитки водными растворами солей. Удобрения, получаемые в определенных условиях, характеризуются способностью к медленному вымыванию нанесенных компонентов водой в течение длительного времени. Ростостимулирующее и пролонгированное действие азотсодержащих биокомпозитных удобрений доказано в вегетативных опытах [11]. Получение удобрений пролонгированного действия на основе древесной коры является актуальным направлением, поскольку основывается на использовании доступного, воспроизводимого вторичного сырья. Древесные подложки способны к гумусообразованию, в отличие от природных цеолитов и других минеральных материалов, предлагаемых для создания аналогичных удобрений.

Следует отметить, что применение удобрений пролонгированного действия имеет существенные преимущества по сравнению с традиционными водорастворимыми удобрениями за счет снижения вымывания питательных элементов грунтовыми и дождевыми водами. В результате снижается уровень загрязнения грунтовых и поверхностных вод в районах земледелия, повышается эффективность использования удобрений, сокращаются расходы на их закупку и др. [14].

Цель настоящей работы - изучение влияния условий получения фосфор-калийных биокомпозитных удобрений на основе пористой подложки из коры лиственницы на их устойчивость к вымыванию фосфатов и калия водой.

\section{Экспериментальная часть}

В качестве сырья для получения пористых подложек биокомпозитных удобрений использовали воз-

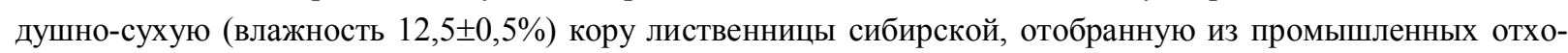
дов. Кору измельчали на дезинтеграторе марки Nossen (Германия), фракционировали и готовили полидисперсную смесь следующего состава, мас. \%: $(0,25-0,50)$ мм - 23,7; $(0,50-1,00)$ мм - 76,3.

Схема получения биокомпозитного удобрения приведена на рисунке 1 . Пористую подложку (ПП) получали обработкой коры лиственницы водным раствором $\mathrm{NaOH}$ при температуре $90{ }^{\circ} \mathrm{C}$ в течение 60 мин и перемешивании с интенсивностью $130 \pm 5$ об./мин. Концентрацию раствора щелочи варьировали от 1 до 5 мас.\%, а значение гидромодуля - от 6 до 16.

По окончании процесса раствор щелочи отделяли фильтрацией и подложку трехкратно промывали водой при комнатной температуре, гидромодуле 5 и перемешивании. Продолжительность каждой промывки составляла 45 мин.

Затем ПП отделяли от промывных вод фильтрацией. Остатки щелочи в ПП нейтрализовали $0,1 \mathrm{~N}$ раствором $\mathrm{HNO}_{3}$ при гидромодуле 5 в течение 30 мин. После отделения раствора кислоты подложку двукратно промывали водой при гидромодуле 5 в течение 30 мин. Стадии промывок и нейтрализации прово-

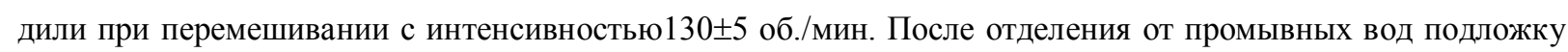
сушили до воздушно-сухого состояния при $50{ }^{\circ} \mathrm{C}$.

Биокомпозитные удобрения (БУ) получали пропиткой подложек из коры водными растворами $\mathrm{KH}_{2} \mathrm{PO}_{4}$ и $\mathrm{K}_{2} \mathrm{HPO}_{4}$ различной концентрации. Количество раствора соли, необходимой для пропитки, соответствовало влагоемкости подложки, которую определяли в соответствии с ГОСТ 24160-80. Количество вводимого в БУ фосфора составляло 3,5 мас. \%. Содержание калия в образцах рассчитывали на основании формул используемых солей $-\mathrm{KH}_{2} \mathrm{PO}_{4}$ и $\mathrm{K}_{2} \mathrm{HPO}_{4} \times 3 \mathrm{H}_{2} \mathrm{O}$. 


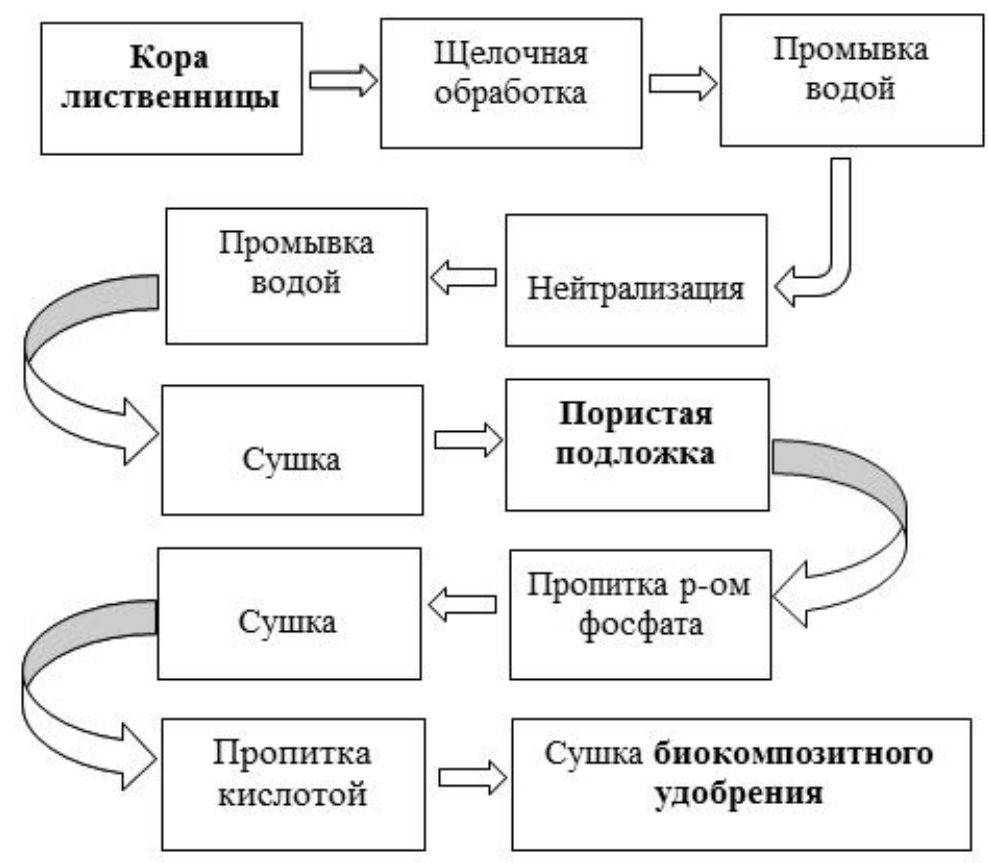

Рис. 1. Схема получения биокомпозитного фосфор-калийного удобрения из коры лиственницы

Пропитанные образцы выдерживали в закрытых бюксах в течение суток при комнатной температуре. Затем образцы высушивали при температурах от 60 до $200{ }^{\circ} \mathrm{C}$.

Обработка образцов БУ кислотой заключалась в их пропитке растворами $\mathrm{HNO}_{3}$ различной концентрации $(0,1-0,5 \mathrm{~N})$. Пропитанные образцы выдерживали в закрытых бюксах при комнатной температуре не менее 2-4 ч и затем сушили при $80-100{ }^{\circ} \mathrm{C}$. Во всех случаях высушивание проводили до воздушносухого состояния образцов БУ.

Определение содержания в подложках из коры лиственницы остаточных водорастворимых веществ (BPB, \%) проводили по общепринятым в химии древесины методикам. Определение в подложках остаточного количества веществ, растворяющихся $1 \%$ раствором $\mathrm{NaOH}$, проводили по методике, описанной в работе [15]. Образцы подложек с различным содержанием остаточных веществ, растворимых в щелочи, готовили на основе ПП, полученной при следующих условиях обработки коры: 1\% раствор NaOH; гидромодуль 10 ; температура обработки $-90{ }^{\circ} \mathrm{C}$; продолжительность - 60 мин. Этот образец подвергали дополнительному экстрагированию 0,5\% раствором щелочи в течение 30-60 мин.

Вымывание фосфатов и калия из образцов БУ проводили в стационарных условиях дистиллированной водой $(\mathrm{pH} 5,4)$ при комнатной температуре. Соотношение образцов БУ и воды в экспериментах составляло 1,5 г к 250 мл. Продолжительность вымывания варьировали от 15 мин до 10 сут. В длительных экспериментах через 24 ч проводили замену водного раствора над образцом БУ.

Концентрацию фосфора в воде определяли методом масс-спектрометрии на приборе ICP-MS 7500 Agilent, а калия - атомно-эмиссионным методом на приборе Analyst-400. По изменению концентраций фосфора и калия в воде рассчитывали величины их вымывания (\%, в пересчете на $\mathrm{P}_{2} \mathrm{O}_{5}$ и $\left.\mathrm{K}_{2} \mathrm{O}\right)$. Исходные количества этих веществ в образцах удобрений принимались равными $100 \%$.

В качестве образца сравнения использовали промышленное гранулированное удобрение «КемираУниверсал 2» (ЗАО «Фертика», Москва). Исходное содержание фосфатов и калия в образце сравнения составляло, мас. \%: 7,6 $\mathrm{P}_{2} \mathrm{O}_{5}$ и 13,5 $\mathrm{K}_{2} \mathrm{O}$.

Опыты по проращиванию семян пшеницы сорта «Новосибирская 15» проводили по методике ГОСТ 12038-84. На увлажненные кипяченной охлажденной водопроводной водой рулоны фильтровальной бумаги наносили 4 г образца подложки из коры лиственницы. Затем на подложку помещали по 60 штук семян и выдерживали в течение 7 дней при температуре $(23 \pm 2){ }^{\circ} \mathrm{C}$. В контрольном опыте использовали только фильтровальную бумагу аналогичного размера, смоченную кипяченой водой. Получаемый эффект оценивали по длине образовавшихся корней и ростков.

Электронно-микроскопические исследования подложки из коры лиственницы и биокомпозитных удобрений на ее основе выполнены на электронном растровом микроскопе ТМ - 1000 (НITАСНІ, Япония). 


\section{Результаты и обсужжение}

\section{Получение пористой подложки из коры лиственницы}

Основным компонентом биокомпозитного удобрения (БУ) является пористая подложка, полученная в результате обработки исходной коры водным раствором щелочи. Условия проведения такой обработки должны обеспечивать наиболее полное удаление полифенольных соединений. Известно, что водорастворимые фенольные соединения способны оказывать ингибирующее действие на развитие растений [16]. Эффективность щелочной обработки оценивали по количеству остаточных водорастворимых веществ в получаемых подложках, поскольку в состав этих веществ могут входить и полифенольные соединения.

Установлено, что изменения концентрации щелочи и гидромодуля в процессе обработки коры лиственницы по-разному влияют на содержание водорастворимых веществ (ВРВ) в пористых подложках (табл. 1).

Увеличение гидромодуля от 6 до 10 приводит к заметному уменьшению содержания ВРВ в подложках. Дальнейшее повышение гидромодуля мало влияет на количество водорастворимых веществ, остающихся в подложках. Для получения подложек с наименьшим содержанием ВРВ целесообразно применять растворы щелочи с концентрацией 1-2\%. В результате применения более концентрированных растворов щелочи содержание ВРВ в подложках увеличивается (табл. 1).

На примере подложки, полученной обработкой коры лиственницы $1 \%$ раствором щелочи при значениях гидромодуля 8 и 10 (температура - $90{ }^{\circ} \mathrm{C}$, продолжительность обработки - 60 мин), изучено влияние содержания ВРВ на проращивание семян пшеницы сорта «Новосибирская 15». Вегетационные тесты показали, что подложки с содержанием остаточных ВРВ в количестве 5,65 и 7,32\% проявили ростостимулирующее влияние - по длине ростков и корней проростки, полученные на этих подложках, превосходят проростки контрольного опыта (рис. 2). Наибольшее ростостимулирующее действие обеспечивает применение подложки, содержащей меньшее количество ВРВ.

Представленные результаты показывают, что пористую подложку для создания биокомпозитных удобрений целесообразно получать при следующих условиях обработки коры лиственницы: 1\% раствор $\mathrm{NaOH}$; гидромодуль - 10; температура обработки - $90{ }^{\circ} \mathrm{C}$; продолжительность - 60 мин.

Текстура подложки, полученной в указанных условиях, представлена крупными порами и полостями с размером от 5 до 60 мкм (рис. 3-1).

Таблица 1. Зависимость содержания водорастворимых веществ в пористых подложках (ПП) от условий щелочной обработки коры лиственницы (температура $90{ }^{\circ} \mathrm{C}$, продолжительность обработки 60 мин)

\begin{tabular}{|c|c|c|c|c|c|}
\hline \multirow{3}{*}{ Гидромодуль } & \multicolumn{5}{|c|}{ Содержание водорастворимых веществ в подложках, \% } \\
\hline & \multicolumn{5}{|c|}{ Концентрация раствора $\mathrm{NaOH}, \%$} \\
\hline & 1 & 2 & 3 & 4 & 5 \\
\hline 6 & 8,63 & 8,55 & 8,72 & 8,87 & 9,32 \\
\hline 8 & 7,32 & 7,30 & 7,37 & 8,12 & 8,64 \\
\hline 10 & 5,65 & 5,64 & 6,38 & 7,46 & 8,15 \\
\hline 12 & 5,48 & 5,49 & 5,52 & 7,22 & 7,54 \\
\hline 14 & 5,41 & 5,39 & 5,41 & 6,78 & 7,12 \\
\hline 16 & 5,37 & 5,36 & 5,43 & 6,67 & 7,14 \\
\hline
\end{tabular}

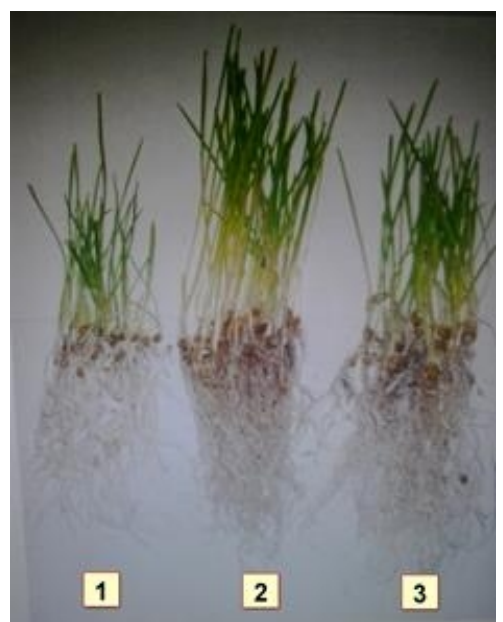

Рис. 2. Результаты проращивания семян пшеницы сорта «Новосибирская 15»: 1 - контрольный опыт (вода); 2 - подложка из коры лиственницы, обработка при гидромодуле 10; 3 - подложка из коры лиственницы, обработка при гидромодуле 8 

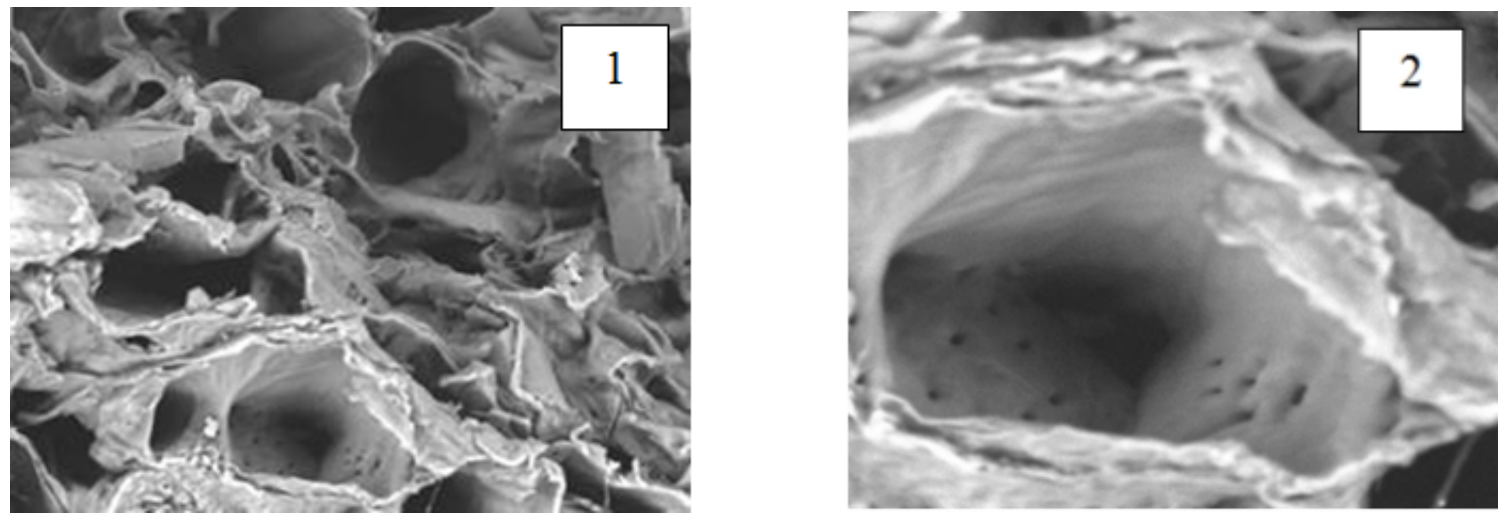

Рис. 3. РЭМ-изображения пористой подложки из коры лиственницы (1) и ее фрагмента (2) (условия получения: $1 \% \mathrm{NaOH}$, гидромодуль 10, температура 90оС, продолжительность обработки 60 мин). Увеличение в 1000 раз

Такая текстура обусловлена анатомическим строением коры лиственницы, состоящей из сплющенных ситовидных клеток, расширенных клеток вертикальной паренхимы, смоляных каналов и др. [17].

На стенках отдельных полостей хорошо видны многочисленные мелкие поры (так называемые «ситовые поля»), соединяющие их с соседними элементами (рис. 3-2). Присутствие в подложке мелких пор может способствовать более равномерному распределению минеральных солей в процессе пропитки подложки их водными растворами.

\section{Получение биокомпозитных удобрений на основе подложки из коры лиственницы}

Известно, что фосфор усваивается корневой системой растений в виде $\mathrm{H}_{2} \mathrm{PO}_{4}^{-}$и $\mathrm{HPO}_{4}{ }^{2-}[18]$. Поэтому для получения БУ применяли водорастворимые соли $\mathrm{KH}_{2} \mathrm{PO}_{4}$ и $\mathrm{K}_{2} \mathrm{HPO}_{4}$.

Было установлено, что природа соли по-разному влияет на вымывание водой калия и фосфатов из получаемых БУ. Так, пористая подложка из коры лучше удерживает калий, нанесенный из раствора $\mathrm{K}_{2} \mathrm{HPO}_{4}$, чем из раствора $\mathrm{KH}_{2} \mathrm{PO}_{4}$, независимо от температуры сушки (рис. $4 \mathrm{a}$ ).

Вероятно, на прочность закрепления калия сказывается различие в характере его химического взаимодействия с поверхностью подложки при нанесении из щелочной $\left(\mathrm{K}_{2} \mathrm{HPO}_{4}\right)$ или кислой $\left(\mathrm{KH}_{2} \mathrm{PO}_{4}\right)$ соли.

Влияние природы соли на вымывание фосфатов проявляется только при температуре сушки подложек $200^{\circ} \mathrm{C}$ (рис. 4б). Большей устойчивостью к вымыванию фосфатов (в 1,75 раз) характеризуется образец удобрения, содержащийК $\mathrm{HPO}_{4}$. Для образцов БУ с гидрофосфатом калия повышение температуры сушки от 100 до $200{ }^{\circ} \mathrm{C}$ обеспечивает уменьшение вымывания фосфатов в 1,8 раз, а калия - в 1,3 раза. На вымывание активных компонентов из БУ, содержащих $\mathrm{KH}_{2} \mathrm{PO}_{4}$, повышение температуры их высушивания влияет мало - достигаемый эффект не превышает $6 \%$ (рис. $4 \mathrm{a}, 6$ ).

Электронно-микроскопические исследования выявили отсутствие кристаллических образований соли на поверхности БУ, высушенного при $200{ }^{\circ} \mathrm{C}$ (рис. 5).

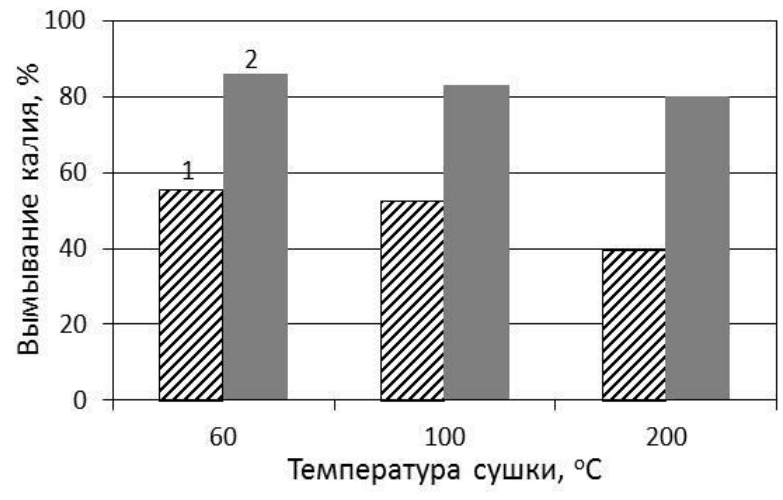

a

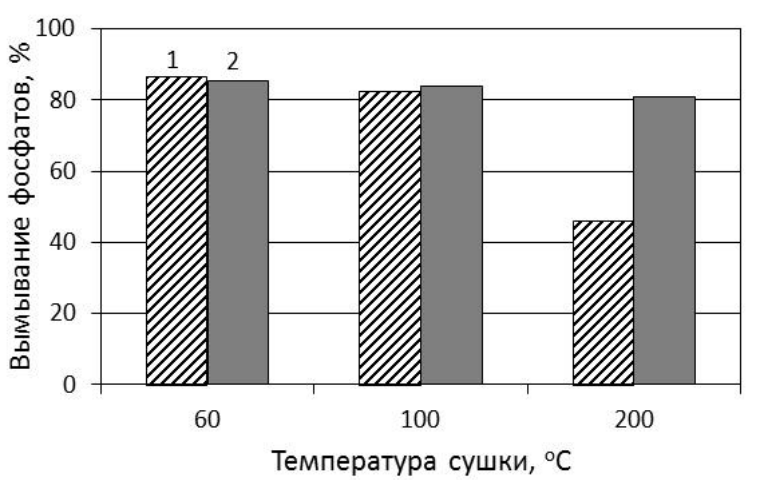

$\sigma$

Рис. 4. Вымывание калия (а) и фосфатов (б) из биокомпозитных удобрений на основе подложки из коры лиственницы в зависимости от температуры сушки (продолжительность вымывания 15 мин): 1 - БУ, содержащие $\mathrm{K}_{2} \mathrm{HPO}_{4} ; 2$ - БУ, содержащие $\mathrm{KH}_{2} \mathrm{PO}_{4}$ 

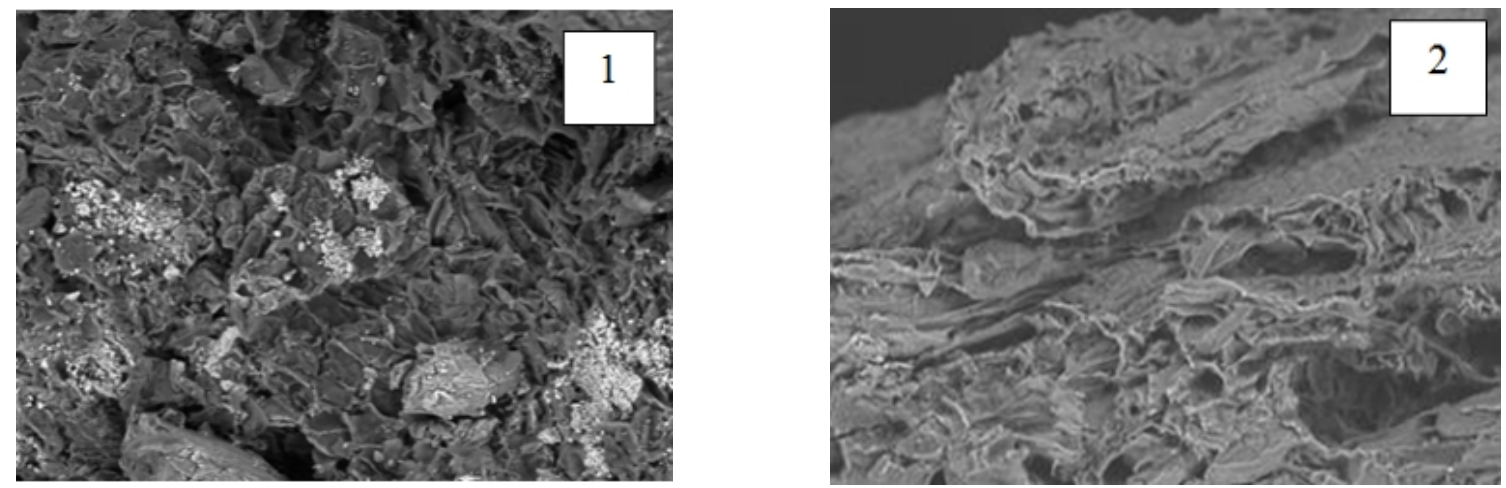

Рис. 5. РЭМ-изображения биокомпозитных удобрений на основе подложки из коры лиственницы, полученных при температурах сушки $100^{\circ} \mathrm{C}(1)$ и $200^{\circ} \mathrm{C}(2)$. Увеличение в 500 раз

Очевидно, что при этой температуре достигается равномерное распределение соли в пористой подложке и малый размер ее частиц.

Наблюдаемый характер распределения соли в образцах удобрений может быть обусловлен изменениями движения фронта испарения, а также деформациями структуры подложки при повышении температуры высушивания [19-21].

Аналогичные изменения в процессе сушки были установлены для биокомпозитных удобрений на основе коры березы, для которых наблюдалось потемнение подложки, пропитанной раствором $\mathrm{K}_{2} \mathrm{HPO}_{4}$ и высушенной при $200{ }^{\circ} \mathrm{C}[13]$.

Поскольку подложка из коры лиственницы имеет достаточно темный цвет, визуальное наблюдение не позволило отметить его изменений в результате пропитки раствором гидрофосфата калия и последующей сушки при $200{ }^{\circ} \mathrm{C}$. Однако было отмечено увеличение интенсивности окрашивания водных вытяжек из такого образца БУ по сравнению с остальными. Очевидно, это вызвано увеличением содержания водорастворимых веществ в образце. Можно предположить, что в результате пропитки подложки из коры лиственницы раствором щелочной соли образуется дополнительное количество растворимых веществ, которые заполняют поры подложки. Присутствие этих веществ в порах биокомпозитного удобрения может создавать дополнительные внутридиффузионные затруднения в процессе вымывания соли водой.

Было установлено, что наличие в подложке из коры веществ, способных растворяться в щелочном реагенте, является важным фактором обеспечения водостойкости биокомпозитных удобрений (табл. 2).

Приведенные в таблице 2 образцы удобрений содержали 3,5 мас.\% фосфора в виде $\mathrm{K}_{2} \mathrm{HPO}_{4}$ и были высушены при $200{ }^{\circ} \mathrm{C}$. Из полученных данных следует, что с уменьшением в подложке количества веществ, способных растворяться в щелочном реагенте, вымывание активных компонентов увеличивается.

Для понижения растворимости веществ, образующихся в подложке при ее пропитке раствором гидрофосфата калия, в схему получения биокомпозитных удобрений включена стадия пропитки разбавленной азотной кислотой (рис. 1). Установлено, что варьирование концентрации азотной кислоты позволяет изменять устойчивость получаемых БУ к вымыванию калия и фосфатов водой (рис. 6).

Таблица 2. Зависимость вымывания калия и фосфатов из биокомпозитных удобрений от содержания в пористых подложках (ПП) растворимых в щелочи веществ (удобрения получены пропиткой $\mathrm{K}_{2} \mathrm{HPO}_{4}$ и высушены при $200^{\circ} \mathrm{C}$ )

\begin{tabular}{c|c|c}
\hline $\begin{array}{c}\text { Количество в ПП веществ, } \\
\text { растворимых в щелочи, \% }\end{array}$ & Вымывание калия, \%* & Вымывание фосфатов, \%* \\
\hline 25,4 & $39,4 \pm 0,3$ & $46,2 \pm 0,3$ \\
17,9 & $41,8 \pm 0,4$ & $49,6 \pm 0,3$ \\
14,5 & $45,3 \pm 0,4$ & $52,8 \pm 0,4$ \\
10,2 & $52,8 \pm 0,5$ & $64,4 \pm 0,4$ \\
8,7 & $62,4 \pm 0,4$ & $73,7 \pm 0,5$ \\
4,5 & $72,6 \pm 0,5$ & $82,4 \pm 0,5$ \\
\hline
\end{tabular}

Примечание. *От исходного содержания калия и фосфатов при продолжительности вымывания 15 мин. 
Максимальный эффект достигается в случае применения для пропитки $0,2-0,3 \mathrm{~N}$ раствора $\mathrm{HNO}_{3}-$ в среднем в 3,8 раз для фосфатов и в 2,1 - для калия. Было установлено, что содержание водорастворимых веществ в образцах удобрений не превышает $4,2 \%$.

Установлено, что в результате кислотной пропитки подложка хуже удерживает калий, что особенно заметно при повышении концентрации кислоты более $0,2 \mathrm{~N}$ (рис. 6). Возможные причины этого могут быть связаны с изменением заряда поверхности подложки и с конкурирующим ионным обменом катионов $\mathrm{K}^{+}$и $\mathrm{H}^{+}$.

Следует отметить, что применение для пропитки $0,1 \mathrm{~N}$ раствора $\mathrm{HNO}_{3}$ позволяет получить удобрение, которое по устойчивости к вымыванию фосфатов сравнимо с удобрением на основе коры березы, полученным в аналогичных условиях [13].

Результаты сопоставления процессов вымывания фосфатов и калия из БУ на основе коры лиственницы и промышленного удобрения «Кемира-Универсал 2» иллюстрируются рисунком 7. Исследуемый образец БУ после нанесения соли был высушен при $200{ }^{\circ} \mathrm{C}$ и пропитан $0,2 \mathrm{~N}$ раствором кислоты.

По устойчивости к вымыванию водой фосфатов и калия биокомпозитное удобрение на основе подложки из коры лиственницы существенно превосходит гранулированное удобрение «КемираУниверсал 2». Следует отметить, что полное вымывание калия из промышленного образца достигается уже через 4 сут. В удобрении на основе древесной подложки через 10 сут. остается 46,7\% калия от его исходного количества, что должно существенно повысить эффективность применения разработанного удобрения по сравнению с промышленным образцом.

Рассчитанные скорости вымывания фосфатов и калия из биокомпозитного удобрения составили 2,19 и 2,52 мас.\%/сут., соответственно. При таких значениях скорости полное вымывание оставшихся в удобрении активных веществ будет достигнуто через 25 и 18 сут., соответственно.

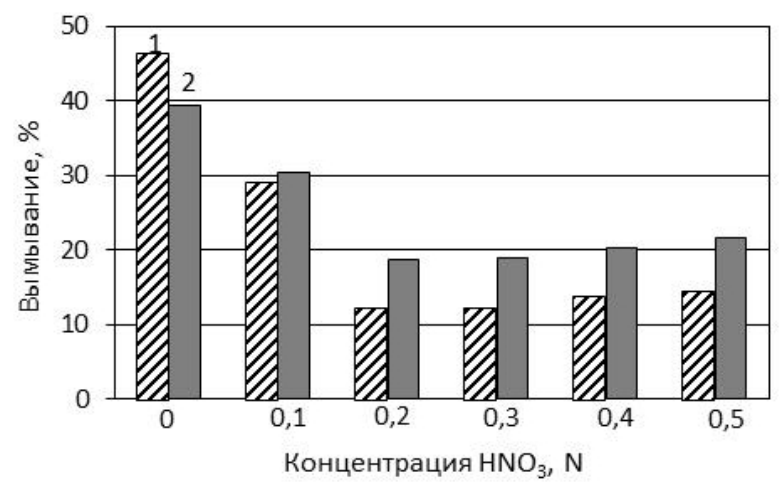

Рис. 6. Влияние концентрации азотной кислоты, применяемой для пропитки, на вымывание фосфатов (1) и калия (2) водой из биокомпозитных удобрений на основе подложки из коры лиственницы (температура сушки $200{ }^{\circ} \mathrm{C}$, продолжительность вымывания 15 мин)

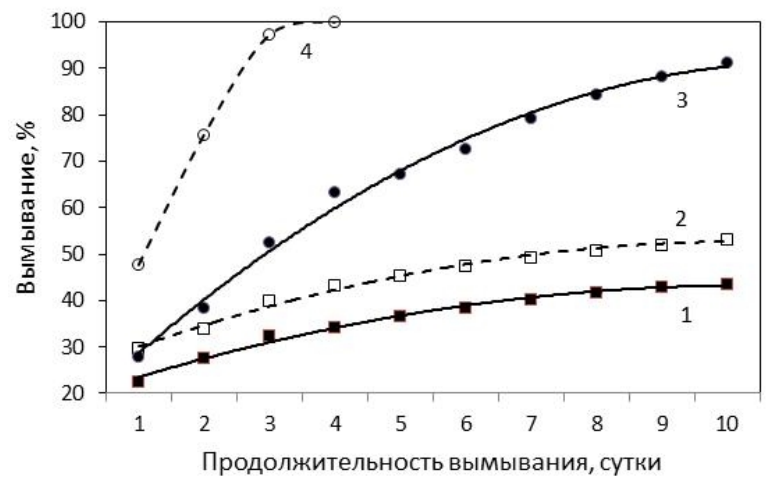

Рис. 7. Вымывание фосфатов $(1,3)$ и калия $(2,4)$ водой: 1 и 2 - вымывание активных компонентов из биокомпозитного удобрения на основе коры лиственницы; 3 и 4 - вымывание из удобрения «Кемира-Универсал 2»

\section{Выводы}

1. На основании проведенных исследований показана возможность получения фосфор-калийного биокомпозитного удобрения с повышенной устойчивостью к вымыванию водой фосфатов и калия путем пропитки пористой подложки из коры лиственницы водным раствором $\mathrm{K}_{2} \mathrm{HPO}_{4}$.

2. Определены условия щелочной обработки коры лиственницы, позволяющие получать пористые подложки с низким содержанием фенольных веществ, токсичных для растений: концентрация раствора $\mathrm{NaOH}-1 \%$; температура обработки $-90^{\circ} \mathrm{C}$; гидромодуль - 10 ; продолжительность обработки - 60 мин.

3. Установлено, что наибольшей устойчивостью к вымыванию фосфатов и калия характеризуются биокомпозитные удобрения, полученные пропиткой подложки гидрофосфатом калия.

4. Показано, что высушивание пропитанной раствором $\mathrm{K}_{2} \mathrm{HPO}_{4}$ подложки при температуре $200^{\circ} \mathrm{C}$ и последующая ее обработка $0,2 \mathrm{~N}$ раствором $\mathrm{HNO}_{3}$ обеспечивает существенное повышение устойчивости 
удобрения к вымыванию водой фосфатов и калия. Из удобрения, полученного в данных условиях, в течение 10 суток вымывается водой 43,6\% фосфатов и 53,3\% калия, что обеспечивает его пролонгированное действие.

5. Разработанное биокомпозитное удобрение на основе коры лиственницы по устойчивости к вымыванию фосфатов и калия превосходит промышленное гранулированное фосфор-калийное удобрение «Кемира-Универсал 2».

\section{Список литературы}

1. Wang L., Li S.J., Liu P.P., Feng G.S., Zhong H. Preparation of a larch bark based composite and its properties // Advanced Materials Research. 2011. Vol. 183-185. Pp. 2005-2009.

2. Иванов И.П., Судакова И.Г., Иванченко Н.М., Кузнецов Б.Н. Изучение свойств активных углей из зерненной коры лиственницы // Химия растительного сырья. 2011. №1. С. 81-86.

3. Кузнецов Б.Н., Левданский В.А., Кузнецова С.А. Химически продукты из древесной коры. Красноярск, 2012.260 с.

4. Бабкин В.А., Остроухова Л.А., Копылова Л.И. Натуральные продукты и их производные, получаемые по технологии замкнутого цикла переработки биомассы лиственницы сибирской // Химия растительного сырья. 2016. №1.C. 121-126.

5. Бабкин В.А., Малков Ю.А., Медведева Е.Н., Неверова Н.А., Левчук А.А. Технология получения биологически активных кормовых добавок из отходов переработки биомассы лиственницы // Химия в интересах устойчивого развития. 2015. Т. 23, №1. С. 19-24.

6. Ivanova N.V., Trofimova N.N., Es'kova L.A., Babrin V.A. The study of the reaction of pectin- $\operatorname{Ag}(0)$ nanocomposites formation // International Journal of Carbohydrate Chemistry. 2012. Article ID 459410. 9 p.

7. Бондарь П.Н., Садыкова В.С. Использование отходов деревообрабатывающей промышленности для создания биопрепаратов на основе грибов Trichoderma // Хвойные бореальной зоны. 2015. Т. XXXIII. №5-6. С. 286-290.

8. Ульянова О.А., Чупрова В.В. Минерализация коры разных видов деревьев и удобрительных композиций на ее основе // Агрохимия. 2015. №2. С. 33-45.

9. Ульянова О.А., Чупрова В.В. Гумификация коры различных видов деревьев и удобрительных композиций на ее основе // Агрохимия. 2016. №5. С. 11-20.

10. Патент 2585193 (РФ). Способ получения натурального красителя из коры лиственницы / А.А. Никифорова, С.М. Жебсаина, И.В. Гаенкова. 2016.

11. Кузнецова С.А., Кузнецов Б.Н., Скурыдина Е.С., Максимов Н.Г., Калачева Г.С., Ульянова О.А., Скворцова Г.П. Синтез и свойства биокомпозитных удобрений на основе мочевины и коры березы // Журнал Сибирского федерального университета. Химия. 2013. Т. 6, №4. С. 380-393.

12. Веприкова Е.В., Кузнецова С.А., Чесноков Н.В., Кузнецов Б.Н. Изучение вымывания КСl водой из биокомпозитных удобрений на основе коры березы // Журнал Сибирского федерального университета. Химия. 2015. T. 8, №1. С. 25-34.

13. Веприкова Е.В., Кузнецова С.А., Чесноков Н.В., Кузнецов Б.Н. Получение и свойства фосфорных биокомпозитных удобрений на основе коры березы // Журнал Сибирского федерального университета. Химия. 2015. T. 8, №3. C. 413-421.

14. Trenkel M.E. Slow- and Controlled - release and stabilized Fertilizers: An option for Enhancing Nutrient Use Efficiency in Agriculture. Secondedition. Paris, 2010. 160 p.

15. Оболенская А.В., Ельницкая 3.П., Леонович А.А. Лабораторные работы по химии древесины и целлюлозы: учеб. пособие для вузов. М., 1991. 320 с.

16. Орлов Д.С., Амосова Я.М., Якименко О.С. Агроэкологические аспекты использования нетрадиционных органических удобрений на основе гидролизного лигнина // Почвоведение. 1993. №2. С. 36-44.

17. Фенгель Д., Вегенер Г. Древесина (химия, ультраструктура, реакции): пер. с англ. М., 1988. 512 с.

18. Безуглова Л.А. Удобрения и стимуляторы роста. Ростов-на-Дону, 2000. 317 с.

19. Промышленный катализ в лекциях. Вып. 1 / под ред. А.С. Носкова. М., 2005. 136 с.

20. Расев А.И. Сушка древесины. СПб., 2010. 410 с.

21. Demiao Chu, Lei Xue, Yu Zhang, Liu Kang Surface characteristics of Poplar wood with high-temperature heat treatment: Wettability and surface brittleness // BioResource. 2016. Vol. 11, no. 3. Pp. 6948-6967.

Поступило в редакиию 2 февраля 2017 г. 
Veprikova E.V..$^{*}$, Chesnokov N.V..$^{1,2}$, Kuznetsov B.N. ${ }^{1,2}$ PREPARATION OF BIOCOMPOSITE PHOSPHORUSPOTASSIUM FERTILIZERS WITH LONG-TIME ACTION ON THE BASE OF A LARCH BARK

${ }^{I}$ Institute of Chemistry and Chemical Technology SB RAS, FRC KSC SB RAS, Akademgorodok, 50-24, Krasnoyarsk 660036 (Russia),e-mail:veprikova2@mail.ru

${ }^{2}$ Siberian Federal University, pr. Svobodny, 79, Krasnoyarsk, 660041 (Russia)

The possibility of preparation of biocomposite fertilizer with a long- time action by impregnation of porous support from larch bark by water solution of $\mathrm{K}_{2} \mathrm{HPO}_{4}$ was shown. The conditions of alkali treatment of a larch bark which can provide porous supports with a low content of the soluble substances toxiferous for plants. The growth stimulate action of porous supports from a larch bark depending on the soluble substances contain into them was revealed at vegetation tests. Effect of salt natural, temperature of an impregnated support drying and conditions of her acid treatment on the phosphates and potassium leaching by water from biocomposite fertilizers was studied. Choice of the preparation conditions providing the greatest resistant of phosphorus-potassium fertilizer for active components leaching by water was held. It was determined, that the fertilizer based on larch bark is able to slow release of active components in long time. In experiments were find that 43,6 \% phosphates and 53,3\% potassium are leaching by water due 10 days from the fertilizer obtained at optimum conditions, that provides their effect of a long-time action. It was shown, that the developed biocomposite phosphorus-potassium fertilizer surpass in resistant to phosphates and potassium leaching a commercial granulated fertilizer.

Keywords: biocomposite fertilizer, larch bark, porous support, impregnation, potassium, phosphates, long-time action.

\section{References}

1. Wang L., Li S.J., Liu P.P., Feng G.S., Zhong H. Advanced Materials Research, 2011, vol. 183-185, pp. $2005-2009$.

2. Ivanov I.P., Sudakova I.G., Ivanchenko N.M., Kuznetsov B.N. Khimiia rastitel'nogo syr'ia, 2011, no. 1, pp. 81-86. (in Russ.).

3. Kuznetsov B.N., Levdanskii V.A., Kuznetsova S.A. Khimicheski produkty iz drevesnoi kory. [Chemically products from the woody bark]. Krasnoyarsk, 2012, 260 p. (in Russ.).

4. Babkin V.A., Ostroukhova L.A., Kopylova L.I. Khimiia rastitel'nogo syr'ia, 2016, no. 1, pp. 121-126. (in Russ.).

5. Babkin V.A., Malkov Iu.A., Medvedeva E.N., Neverova N.A., Levchuk A.A. Khimiia v interesakh ustoichivogo razvitiia, 2015, vol. 23, no. 1, pp. 19-24. (in Russ.).

6. Ivanova N.V., Trofimova N.N., Eskova L.A., Babkin V.A. International Journal of Carbohydrate Chemistry, 2012, Article ID 459410.9 p.

7. Bondar' P.N., Sadykova V.S. Khvoinye boreal'noi zony, 2015, vol. XXXIII, no. 5-6, pp. 286-290. (in Russ.).

8. Ul'ianova O.A., Chuprova V.V. Agrokhimiia, 2015, no. 2, pp. 33-45. (in Russ.).

9. Ul'ianova O.A., Chuprova V.V. Agrokhimiia, 2016, no. 5, pp. 11-20. (in Russ.).

10. Patent 2585193 (RU). 2016. (in Russ.).

11. Kuznetsova S.A., Kuznetsov B.N., Skurydina E.S., Maksimov N.G., Kalacheva G.S., Ul'ianova O.A., Skvortsova G.P. Zhurnal sibirskogo federal'nogo universiteta. Khimiia, 2013, vol. 6, no. 4, pp. 380-393. (in Russ.).

12. Veprikova E.V., Kuznetsova S.A., Chesnokov N.V., Kuznetsov B.N. Zhurnal sibirskogo federal'nogo universiteta. Khimiia, 2015, vol. 8, no. 1, pp. 25-34. (in Russ.).

13. Veprikova E.V., Kuznetsova S.A., Chesnokov N.V., Kuznetsov B.N. Zhurnal sibirskogo federal'nogo universiteta. Khimiia, 2015, vol. 8, no. 3, pp. 413-421. (in Russ.).

14. Trenkel M.E. Slow- and Controlled - release and stabilized Fertilizers: An option for Enhancing Nutrient Use Efficiency in Agriculture. Secondedition. Paris, 2010. 160 p.

15. Obolenskaia A.V., El'nitskaia 3.P., Leonovich A.A. Laboratornye raboty po khimii drevesiny i tselliulozy. [Laboratory work on the chemistry of wood and cellulose]. Moscow, 1991, 320 p. (in Russ.).

16. Orlov D.S., Amosova Ia.M., Iakimenko O.S. Pochvovedenie, 1993, no. 2, pp. 36-44. (in Russ.).

17. Fengel' D., Vegener G. Drevesina (khimiia, ul'trastruktura, reaktsii). [Wood (chemistry, ultrastructure, reactions)]. Moscow, 1988, 512 p. (in Russ.).

18. Bezuglova L.A. Udobreniia i stimuliatory rosta. [Fertilizers and growth stimulators]. Rostov-on-Don, 2000,317 p. (in Russ.).

19. Promyshlennyi kataliz v lektsiiakh. [Industrial catalysis in lectures]. Issue 1. Ed. A.S. Noskov, Moscow, 2005,136 p. (in Russ.).

20. Rasev A.I. Sushka drevesiny. [Drying of wood]. St. Petersburg, 2010, 410 p. (in Russ.).

21. Demiao Chu, Lei Xue, Yu Zhang, Liu Kang. BioResource, 2016, vol. 11, no. 3, pp. 6948-6967.

Received February 2, 2017

Revised May 5, 2017

\footnotetext{
* Corresponding author.
} 
